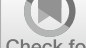

Check for

updates

Cite as

Nano-Micro Lett.

(2020) 12:146

Received: 15 April 2020

Accepted: 3 June 2020

Published online: 13 July 2020

(C) The Author(s) 2020

\section{Sandwiching Sulfur into the Dents Between N, O Co-Doped Graphene Layered Blocks with Strong Physicochemical Confinements for Stable and High-Rate Li-S Batteries}

\author{
Mengjiao Shi ${ }^{1}$, Su Zhang ${ }^{2}$, Yuting Jiang ${ }^{1}$, Zimu Jiang $^{1}$, Longhai Zhang ${ }^{1}$, Jin Chang ${ }^{1}$, \\ Tong Wei ${ }^{1,3} \bowtie$, Zhuangjun Fan ${ }^{1,3} \bowtie$ \\ Mengjiao Shi and Su Zhang have contributed equally to this work. \\ \Tong Wei, weitong666@163.com; Zhuangjun Fan, fanzhj666@163.com \\ 1 Key Laboratory of Superlight Materials and Surface Technology, Ministry of Education, College \\ of Material Science and Chemical Engineering, Harbin Engineering University, Harbin 150001, \\ People's Republic of China \\ 2 Key Laboratory of Energy Materials Chemistry, Ministry of Education, Key Laboratory of Advanced \\ Functional Materials, Autonomous Region, Institute of Applied Chemistry, Xinjiang University, \\ Urumqi 830046, People's Republic of China \\ 3 State Key Laboratory of Heavy Oil Processing, School of Materials Science and Engineering, China \\ University of Petroleum, Qingdao 266580, People's Republic of China
}

\title{
HIGHLIGHTS
}

- $\mathrm{N}, \mathrm{O}$ co-doped graphene layered block (NOGB) was prepared as sulfur host for lithium-sulfur batteries.

- The NOGB/S shows good rate performance due to robust electrochemical kinetics.

- The strong physicochemical confinement leads to an improved cycling stability.

\begin{abstract}
The development of lithium-sulfur batteries (LSBs) is restricted by their poor cycle stability and rate performance due to the low conductivity of sulfur and severe shuttle effect. Herein, an N, O co-doped graphene layered block (NOGB) with many dents on the graphene sheets is designed as effective sulfur host for high-performance LSBs. The sulfur platelets are physically confined into the

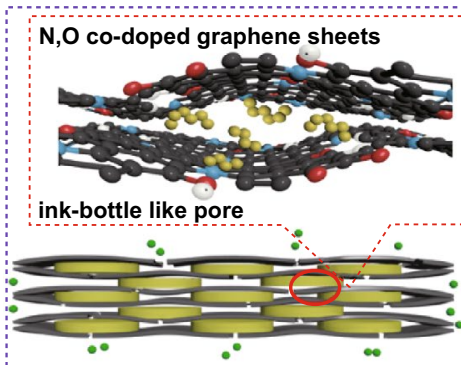
N,O co-doped graphene layered-blocks 1. strong physicochemical confinement 2. good structure stability

3. entire conductive network

4. abundant ion transport paths
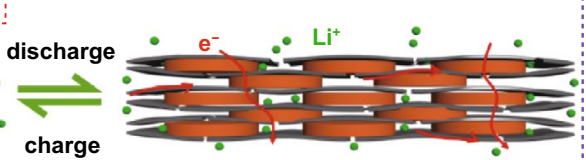
dents and closely contacted with the graphene scaffold, ensuring structural stability and high conductivity. The highly doped $\mathrm{N}$ and $\mathrm{O}$ atoms can prevent the shuttle effect of sulfur species by strong chemical adsorption. Moreover, the micropores on the graphene sheets enable fast $\mathrm{Li}^{+}$transport through the blocks. As a result, the obtained NOGB/S composite with $76 \mathrm{wt} \%$ sulfur content shows a high capacity of $1413 \mathrm{mAh} \mathrm{g}^{-1}$ at $0.1 \mathrm{C}$, good rate performance of $433 \mathrm{mAh} \mathrm{g}^{-1}$ at $10 \mathrm{C}$, and remarkable stability with $526 \mathrm{mAh} \mathrm{g}^{-1}$ at after 1000 cycles at $1 \mathrm{C}$ (average decay rate: $0.038 \%$ per cycle). Our design provides a comprehensive route for simultaneously improving the conductivity, ion transport kinetics, and preventing the shuttle effect in LSBs.
\end{abstract}

KEYWORDS Graphene; Physicochemical confinement; Cycle stability; Shuttle effect; Li-S batteries 


\section{Introduction}

Lithium-sulfur batteries (LSBs) have attracted widespread attention owing to the high theoretical specific capacity (1675 $\mathrm{mAh} \mathrm{g}^{-1}$ ), low cost, and natural abundance of sulfur $[1,2]$. However, the application of LSBs is severely restricted by two issues: low sulfur utilization due to the sluggish electrochemical kinetics of the non-conductive sulfur; fast capacity decay from the large volume expansion $(\sim 80 \%)$ and the shuttle effect of lithium polysulfides $\left(\mathrm{Li}_{2} \mathrm{~S}_{x}, 4 \leq x \leq 8\right)$ during charge-discharge process [3, 4]. To overcome these problems, various approaches such as developing multifunctional sulfur hosts [2], configuring with modified separators [5-9], and modifying the electrolyte with additives [10-13] have been developed previously $[14,15]$. Among them, one of the most promising ways is to confine sulfur into conductive porous carbon scaffolds.

Researchers have made significant efforts on designing conductive carbon hosts such as hollow carbon spheres [16-18], activated carbons [19, 20], carbon nanotubes/fibers [5, 21, 22], and graphene nanosheets [4, 23, 24] for simultaneously improving the conductivity and physical confining sulfur species. However, the physical confinement by carbon hosts is not sufficient to suppress the shuttle effect over long-term cycling because of the weak interaction between the nonpolar carbon hosts and polar polysulfides [25]. Besides, the large volume expansion of sulfur during lithiation also causes the serious dissolution of the polysulfides out of the nanopores. To overcome this issue, researchers proposed a chemisorption method of polysulfides by doping heteroatoms or compounding metal compounds (e.g., $\mathrm{MoS}_{2}$ [26, 27], $\mathrm{MoSe}_{2}$ [28], $\mathrm{TiO}_{2}$ [29-31], and $\left.\mathrm{MnO}_{2}[32,33]\right)$ in carbon scaffolds. Particularly, nitrogen and/or oxygen doping has been proved to be a simple but effective way for enhancing the chemisorption ability of lithium polysulfides through the formation of strong $\mathrm{Li}-\mathrm{N} / \mathrm{O}$ bonds as well as improving the surface polarity [25, 34-37]. As a result, a promising carbon host could provide large free space for physically confining sulfur species and buffering the volumetric expansion, strong chemisorption of polysulfides for suppressing the shuttle effect, and highly conductive network for improving the electrochemical kinetics.

Herein, we report a rational designed N, O co-doped graphene layered block (NOGB) with many dents on the graphene sheets as sulfur host to improve the stability and rate performance of LSBs, as shown in Scheme 1. The graphene oxide $/ \mathrm{MnO}_{2}$ nanowires layered stacking composite was first prepared by the modified Hummers' method yet without removing the $\mathrm{MnO}_{2}$. Then, the NOGB was prepared by thermal treatment of the composite in the $\mathrm{NH}_{3}$ atmosphere and subsequent removing the resulted $\mathrm{MnO}$ nanoplatelets. Due to the $\mathrm{MnO}$ nanoplatelets as spacers, there are many dents on the graphene sheets. This unique structure can effectively suppress the shuttle effect of polysulfides by the strong physicochemical confinement. Moreover, the close contact

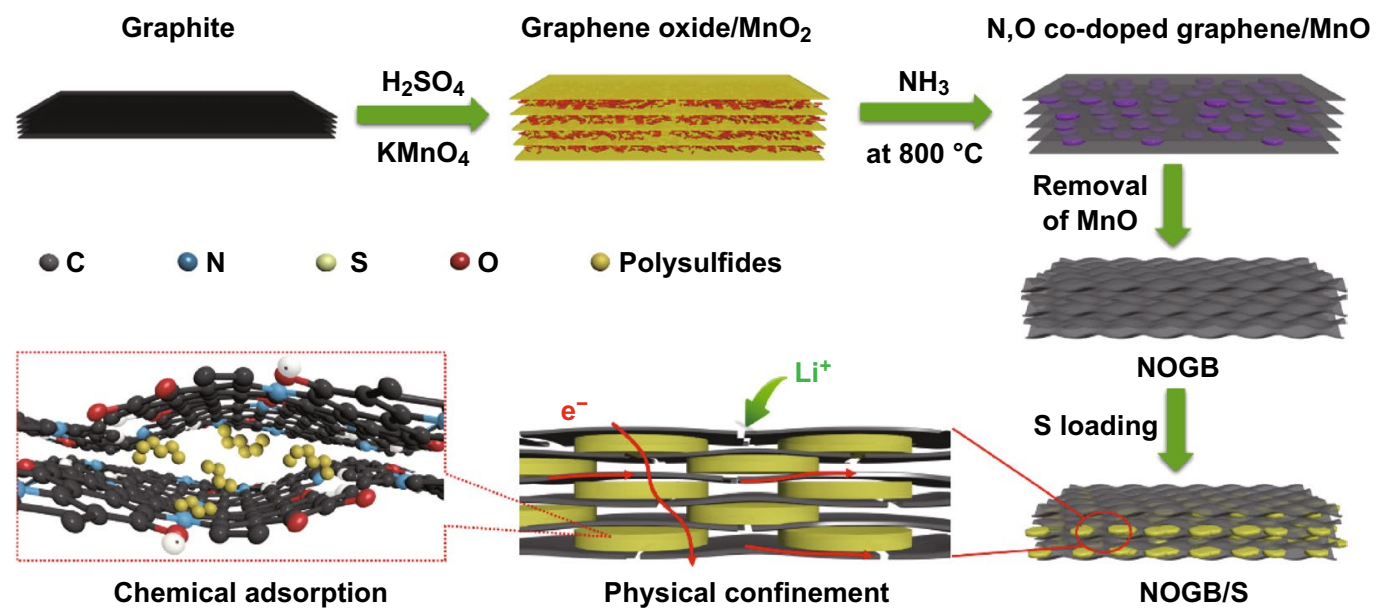

Scheme 1 Preparation process of the NOGB/S composite 
between graphene and sulfur platelets and abundant micropores on the graphene sheets as ion migration channels enable the NOGB/S composite with robust electrochemical kinetics. The NOGB/S with a high sulfur content of $76 \mathrm{wt} \%$ shows a high capacity of $1413 \mathrm{mAh} \mathrm{g}^{-1}$ at $0.1 \mathrm{C}$, high rate performance of $433 \mathrm{mAh} \mathrm{g}^{-1}$ at $10 \mathrm{C}$, and remarkable stability with $526 \mathrm{mAh} \mathrm{g}^{-1}$ after 1000 cycles at $1 \mathrm{C}$ (average decay rate: $0.038 \%$ per cycle), which are among the best of the reported results.

\section{Experimental Section}

\subsection{Material Synthesis}

\subsubsection{Synthesis of NOGB}

Graphene oxide/ $\mathrm{MnO}_{2}$ nanowires composite was prepared by the modified Hummers' method [38]. Typically, $5 \mathrm{~g}$ natural graphite powder was added into $115 \mathrm{~mL}$ concentrated $\mathrm{H}_{2} \mathrm{SO}_{4}$ at $0{ }^{\circ} \mathrm{C}$ under vigorous magnetic stirring for $0.5 \mathrm{~h}$; then, $30 \mathrm{~g}$ $\mathrm{KMnO}_{4}$ was added and stirring at $\sim 38^{\circ} \mathrm{C}$ for $2 \mathrm{~h}$. The mixture temperature was adjusted to $70^{\circ} \mathrm{C}$ by adding $230 \mathrm{~mL}$ deionized (DI) water and stirred for another $2 \mathrm{~h}$ to obtain graphene oxide $/ \mathrm{MnO}_{2}$ slurry. The graphene oxide $/ \mathrm{MnO}_{2}$ composite was obtained by lyophilization after washing the slurry with DI water to neutral. After that, the graphene oxide/ $\mathrm{MnO}_{2}$ was treated in an ammonia atmosphere at $800{ }^{\circ} \mathrm{C}$ for $2 \mathrm{~h}$ with the heating rate of $3{ }^{\circ} \mathrm{C} \mathrm{min}^{-1}$ to get $\mathrm{N}, \mathrm{O}$ co-doped graphene/ $\mathrm{MnO}$ composite. Subsequently, the composite was washed by a mixture of $80 \mathrm{~mL} 0.1 \mathrm{M} \mathrm{H}_{2} \mathrm{SO}_{4}$ and $10 \mathrm{~mL} \mathrm{H}_{2} \mathrm{O}_{2}$ solution (35 wt \%) and DI water repeatedly to remove the MnO. Finally, the NOGB was obtained by lyophilization.

For comparison, graphene block (GB) without $\mathrm{N}$ doping was prepared by the same process as NOGB except thermal treatment in the $\mathrm{N}_{2}$ atmosphere. Reduced graphene oxide (RGO) was prepared by thermal treatment of graphene oxide in $\mathrm{N}_{2}$ atmosphere at $800^{\circ} \mathrm{C}$ for $2 \mathrm{~h}$ with the heating rate of $3^{\circ} \mathrm{C} \mathrm{min}^{-1}$.

\subsubsection{Synthesis of NOGB/S Composites}

Typically, NOGB was mixed with sublimed sulfur $(99.98 \%$, Sinopharm) at a mass ratio of 1:4. The mixture was heated to $155^{\circ} \mathrm{C}$ and kept for $12 \mathrm{~h}$ in a $\mathrm{N}_{2}$ atmosphere. After cooling down to room temperature, the NOGB/S with the sulfur content of $76 \mathrm{wt} \%$ was obtained. For comparison, the GB/S and $\mathrm{RGO} / \mathrm{S}$ composites were also prepared by the same process with both $71 \mathrm{wt} \%$ sulfur content.

\subsection{Material Characterizations}

The structural characterizations were conducted by scanning electronic microscopy (SEM, CamScan Mx2600FE) and transmission electronic microscopy (TEM, JEOL JEM-2010). X-ray diffraction patterns and Raman spectra of the as-prepared samples were measured by a Bruker D8 Discovery X-ray diffractometer and a Jobin-Yvon HR800 Raman spectrometer with $532 \mathrm{~nm}$ wavelength incident laser light. X-ray photoelectron spectroscopy (XPS) measurement was taken on a PerkinElmer PHI5700 ESCA System with monochromated Al K $\alpha$ radiation (energy $1486.6 \mathrm{eV}$ ). Thermogravimetric analysis (TGA, STA 449 F5) was used to measure the mass contents of sulfur in the composites. $\mathrm{N}_{2}$ adsorption-desorption isotherm at 77.4 K (Quantachrome IQ2) was characterized the pore structures and specific surface area of the samples using the Barrett-Joyner-Halenda (BJH) method and Brunauer-Emmett-Teller (BET) method, respectively. The microporous structure of NOGB is measured by the $\mathrm{CO}_{2}$ adsorption-desorption isotherm at $0{ }^{\circ} \mathrm{C}$.

\subsection{Electrochemical Measurements}

The standard 2032 coin-type cell was used for measuring the electrochemical performance of the samples. The cathode slurry was prepared by mixing the as-prepared sample (70 wt $\%)$, conductive carbon black (20 wt $\%$ ), and poly(vinylidene fluoride) binder (10 wt $\%)$ in an $N$-methyl-2-pyrrolidone solvent. The slurry was then cast onto an aluminum foil, dried at $60{ }^{\circ} \mathrm{C}$ for $12 \mathrm{~h}$ in a vacuum oven to prepare cathode electrode. The areal sulfur loading of the electrodes was about $1.2 \mathrm{mg} \mathrm{cm}^{-2}$. The electrochemical performance of the NOGB/S electrodes with a high sulfur loading of $4.4 \mathrm{mg} \mathrm{cm}^{-2}$ was also measured. The electrolyte used was $1 \mathrm{M}$ lithium bis(trifluoromethanesulfonyl) imide (LiTFSI) and $2 \mathrm{wt} \%$ lithium nitrate $\left(\mathrm{LiNO}_{3}\right)$ dissolved in $1: 1(\mathrm{v} / \mathrm{v})$ 1,3-dioxolane/1,2-dimethoxyethane (DOL/DME). The 
electrolyte-to-sulfur ratio for the coin cell assembly was controlled as ca. $20 \mu \mathrm{L} \mathrm{mg}^{-1}$ for the sulfur loading of $1.2 \mathrm{mg} \mathrm{cm}^{-2}$ and $12 \mu \mathrm{L} \mathrm{mg}^{-1}$ for the sulfur loading of $4.4 \mathrm{mg} \mathrm{cm}^{-2}$ according to the previous works [22, 37]. Then, the cells consisting of the cathode electrode, a Celgard 2300 separator, a lithium metal anode were assembled in an argon-filled glove box. Galvanostatic charge-discharge at different currents was tested in a voltage range of 1.6-2.8 V using a battery test system (Wuhan LAND, CT2100A, China). Cyclic voltammetry (CV) with a scan rate of $0.1 \mathrm{mV} \mathrm{s}^{-1}$ between $1.6-2.8 \mathrm{~V}$ and electrochemical impedance spectroscopy (EIS) were performed on an electrochemical station (Autolab PGSTAT302N). Fresh batteries were used for the EIS test at the open-circuit potential. The frequency is ranging from $100 \mathrm{kHz}$ to $10 \mathrm{mHz}$ at a voltage amplitude of $5 \mathrm{mV}$. The capacities were calculated based on the mass of sulfur.

\section{Results and Discussion}

Scheme 1 illustrates the preparation process of the NOGB and the NOGB/S composite. $\mathrm{KMnO}_{4}$ is intercalated between the graphite layers and then reduced to uniformly distributed $\mathrm{MnO}_{2}$ nanowires [38], leading to the formation of a graphene oxide/ $\mathrm{MnO}_{2}$ sandwich structure (Fig. 1a). Through thermal treatment at $800{ }^{\circ} \mathrm{C}$ in $\mathrm{NH}_{3}$ atmosphere, the $\mathrm{MnO}_{2}$ nanowires are converted to $\mathrm{MnO}$ nanoplatelets due to the interlayer confinement, simultaneous leading to the nitrogen doping of the graphene (Figs. 1b, e and S1). After removing the $\mathrm{MnO}$ nanoplatelets, the obtained NOGB maintains the block appearance with many dents between the stacking layers (Fig. 1c, f). The sulfur is then loaded into NOGB through melting diffusion, and there are no obvious agglomerated sulfur particles on the surface of NOGB/S (Fig. 1g, h), indicating the full incorporation of sulfur into the dents of the graphene sheets. For comparison, the GB/S with the similar
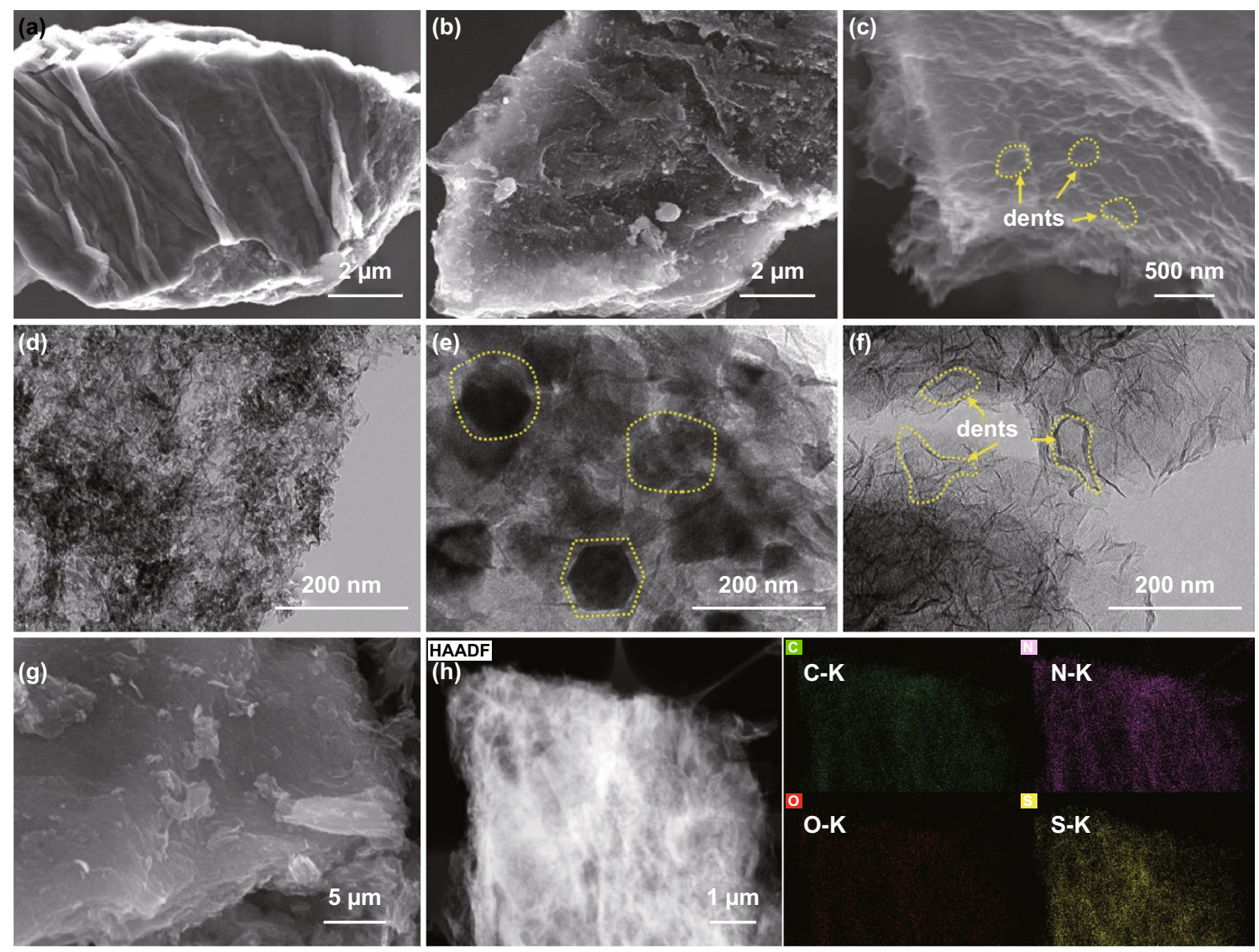

Fig. 1 SEM images of a graphene oxide/ $\mathrm{MnO}_{2}$, b $\mathrm{N}, \mathrm{O}$ co-doped graphene/MnO, and $\mathbf{c}$ NOGB. TEM images of $\mathbf{d}$ graphene oxide/MnO , e $\mathrm{N}$, O co-doped graphene/MnO, and $\mathbf{f}$ NOGB. $\mathbf{g}$ SEM images of the NOGB/S. h STEM image of the NOGB/S and the corresponding elemental mapping images of carbon, nitrogen, oxygen, and sulfur 
structure as NOGB/S also shows no obvious sulfur particles (Fig. S2), but many large sulfur particles are observed on the surface of RGO/S (Fig. S2). Thus, the RGO with an open structure cannot encapsulate sulfur species effectively. The element distribution of NOGB/S further confirms that $\mathrm{N}$ element is homogeneous distribution in the block skeleton, and sulfur is well confined in the NOGB host (Fig. 1h). This indicates the strong capillary absorption of sulfur by the special dent structure of NOGB.

$\mathrm{XRD}$ was performed to investigate the composition and crystalline structure evolution of the products. As shown in Fig. S3, the $\mathrm{MnO}_{2}$ in graphene oxide/ $\mathrm{MnO}_{2}$ show a tetragonal $\alpha-\mathrm{MnO}_{2}$ phase (JCPDS No. 04-0141). After calcination at $800{ }^{\circ} \mathrm{C}$, the $\mathrm{MnO}_{2}$ is converted to cubic phase $\mathrm{MnO}$ in the $\mathrm{N}$, O co-doped graphene/MnO (JCPDS No. 07-0230, Fig.
S3). The NOGB, GB, and RGO show the similar dispersive diffraction peak (002) at $\sim 25^{\circ}$, indicating their thin layer stacking structure (Figs. 2a and S4) [39]. After impregnating with sulfur, a series of sharp diffraction peaks in the composite materials correspond to the orthorhombic sulfur (JCPDS No. 08-0247). It should be noticed that the diffraction peaks of sulfur in the NOGB/S and GB/S are weaker than those in $\mathrm{RGO} / \mathrm{S}$, indicating that the sulfur shows a thin layer structure with low crystallinity due to the confinement in the dents of the graphene blocks (Fig. 1e, h). The contents of sulfur impregnated in NOGB, GB, and RGO obtained by the TG analysis are 76, 71, and $71 \mathrm{wt} \%$ (Fig. S5), respectively. In the Raman spectra of NOGB, GB, and RGO (Fig. S6), two peaks at $1358 \mathrm{~cm}^{-1}$ (D-band) and $1580 \mathrm{~cm}^{-1}$ (G-band) are assigned to the disordered and graphitic regions in graphene,
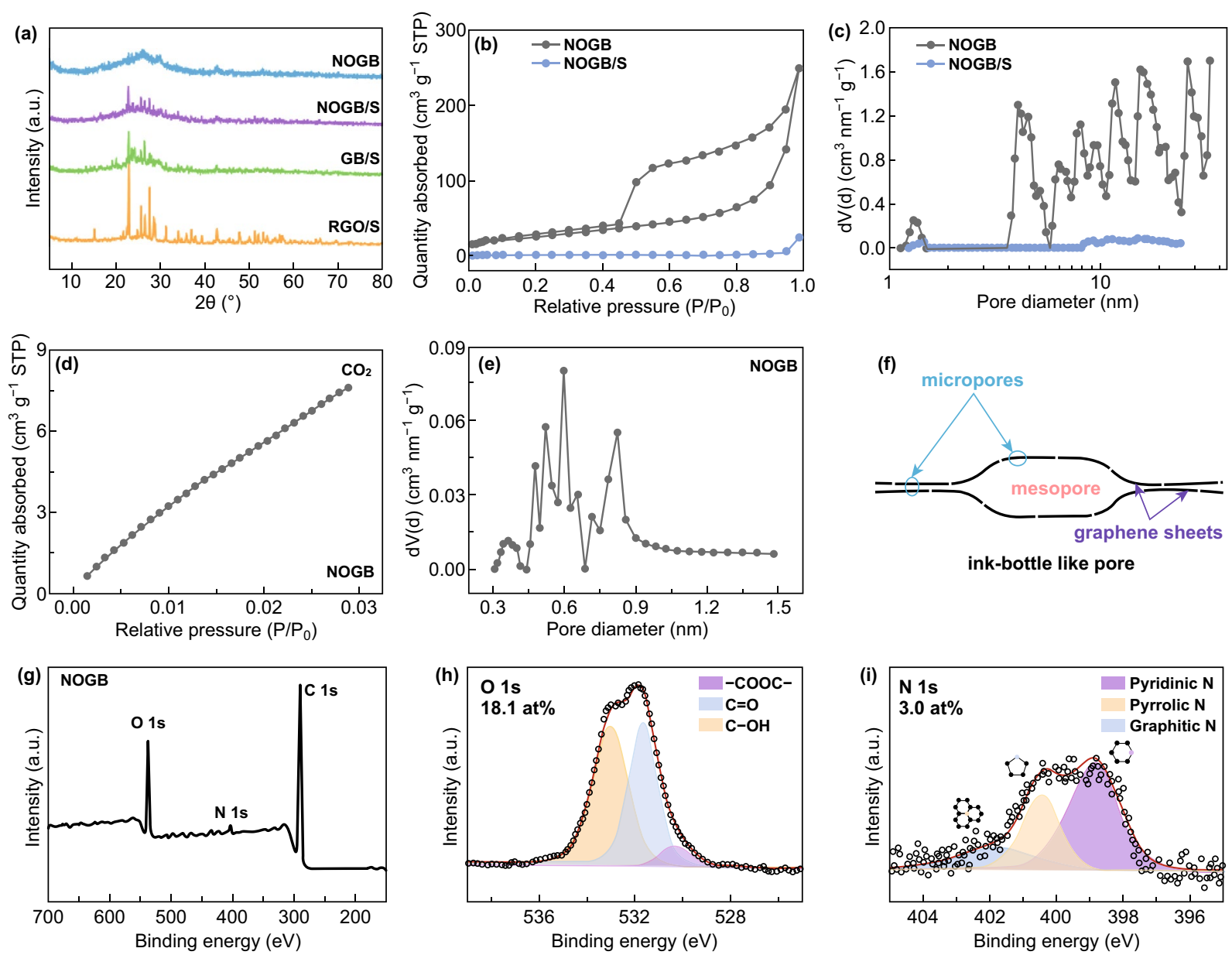

Fig. 2 a XRD patterns of the NOGB, RGO/S, GB/S, and NOGB/S. $\mathbf{b} \mathrm{N}_{2}$ adsorption-desorption isotherms of the NOGB and NOGB/S and $\mathbf{c}$ corresponding pore size distribution. $\mathbf{d ~ C O}$ adsorption-desorption isotherm of NOGB and $\mathbf{e}$ corresponding micropore size distribution. $\mathbf{f}$ Schematic illustration of the porous structure of the NOGB. $\mathbf{g}$ XPS survey spectrum, $\mathbf{h} \mathrm{O} 1 \mathrm{~s}$, and $\mathbf{i} \mathrm{N} 1 \mathrm{~s}$ spectra of the NOGB 
respectively [40]. The NOGB shows the lowest $I_{D} / I_{G}$ ratio of 0.91 among the samples (GB: 0.93, RGO: 0.97), implying good electrical conductivity.

The specific surface areas and porous structure of the NOGB and NOGB/S are obtained by the $\mathrm{N}_{2}$ adsorption-desorption isotherms (Fig. 2b-e and Table S1). The NOGB has a surface area of $92.72 \mathrm{~m}^{2} \mathrm{~g}^{-1}$ with a large pore volume of $0.382 \mathrm{~cm}^{3} \mathrm{~g}^{-1}$. Importantly, it shows a typical IV-type sorption behavior and a H2-type hysteresis loops with an obvious hysteresis loop at the middle and high-relative-pressure region (0.4-1.0), indicating that the dents on graphene sheets with the width of 3-10 nm show an "ink-bottle"like mesoporous structure (Fig. 2f). This porous structure is much favorable for trapping sulfur species during charge-discharge. After impregnation of sulfur, the surface area and pore volume of the NOGB/S drastically decrease to $2.560 \mathrm{~m}^{2} \mathrm{~g}^{-1}$ and $0.037 \mathrm{~cm}^{3} \mathrm{~g}^{-1}$, revealing that the thin sulfur nanoplatelets are fully contacted with the conductive graphene networks. $\mathrm{CO}_{2}$ adsorption-desorption is a powerful method to determine the microporous structure of materials. From the isotherm given in Fig. 2d, e, some micropores with a size distribution of $0.4-0.8 \mathrm{~nm}$ are formed on the graphene sheets of NOGB due to the decomposition of functional groups during the heating treatment (Fig. 2f). These micropores can play as $\mathrm{Li}^{+}$migration channels during charge-discharge, enabling high rate performance.

The doped $\mathrm{N}$ and $\mathrm{O}$ groups in carbon scaffold, especially pyridinic $\mathrm{N}$, are vital for the chemical adsorption of polysulfides during charge-discharge through the strong $\mathrm{S}_{x} \mathrm{Li}-\mathrm{N} / \mathrm{O}$ interactions [41]. The chemical compositions and states of the NOGB, GB, and RGO are investigated by XPS analysis, as shown in Figs. 2g-i and S7. The peaks at around 286, 400, and $532 \mathrm{eV}$ correspond to the $\mathrm{C} 1 \mathrm{~s}, \mathrm{~N} 1 \mathrm{~s}$, and $\mathrm{O}$ 1s for NOGB. The contents of $\mathrm{C}, \mathrm{N}$, and $\mathrm{O}$ are 78.9, 3.0, and 18.1 at $\%$, respectively. The NOGB shows the highest $\mathrm{N}$ and O content than that of GB and RGO (Table S2). The XPS $\mathrm{N}$ 1s spectrum of NOGB (Fig. 2i) can be deconvoluted into three peaks corresponding to the pyridinic $\mathrm{N}(398.1 \mathrm{eV})$, pyrrolic $\mathrm{N}(399.8 \mathrm{eV})$, and graphitic $\mathrm{N}(401.8 \mathrm{eV})$. And the $\mathrm{O} 1 \mathrm{~s}$ spectrum shows three peaks at 530.6, 531.6, and $533.2 \mathrm{eV}$ assigning to lactones $\mathrm{O}$ (-COOC-), carbonyl $\mathrm{O}$ $(\mathrm{C}=\mathrm{O})$, and hydroxyl $\mathrm{O}(\mathrm{C}-\mathrm{OH})$, respectively [42]. The contents of $\mathrm{N}$ and $\mathrm{O}$ are calculated based on XPS results and shown in Table S2. The NOGB possesses abundant polar functional groups such as pyridinic $\mathrm{N}$, pyrrolic $\mathrm{N}$, carbonyl $\mathrm{O}$, and hydroxyl $\mathrm{O}$, which can effectively adsorb polysulfides
[42]. Besides, the graphitic $\mathrm{N}$ can improve the electrical conductivity of the NOGB [34].

Figure $3 \mathrm{a}$ presents the first cyclic voltammetry $(\mathrm{CV})$ curves of $\mathrm{NOGB} / \mathrm{S}, \mathrm{GB} / \mathrm{S}$, and $\mathrm{RGO} / \mathrm{S}$ at the scan rate of $0.1 \mathrm{mV} \mathrm{s}^{-1}$. The two reduction peaks at around 2.35 and $2.1 \mathrm{~V}$ correspond to the conversion of sulfur to long-chain soluble lithium polysulfides $\left(\operatorname{Li}_{2} \mathrm{~S}_{x}, 4 \leq x \leq 8\right)$, further to short-chain insoluble discharge products $\left(\mathrm{Li}_{2} \mathrm{~S}_{2} / \mathrm{Li}_{2} \mathrm{~S}\right)$. The distinct oxidation peak at about $2.4 \mathrm{~V}$ is ascribed to the transformation of $\mathrm{LiS}_{2} / \mathrm{Li}_{2} \mathrm{~S}_{2}$ to $\mathrm{S}_{8}$ [43]. The sharp shoulder peak at $2.36 \mathrm{~V}$ of $\mathrm{NOGB} / \mathrm{S}$ corresponds to the conversion of $\mathrm{LiS}_{2} / \mathrm{Li}_{2} \mathrm{~S}_{2}$ to $\mathrm{Li}_{2} \mathrm{~S}_{4-8}$ and then final to $\mathrm{S}_{8}$ [41]. But in GB/S and $\mathrm{RGO} / \mathrm{S}$, this shoulder peak is merged to the main peak at 2.38 and $2.50 \mathrm{~V}$, respectively. And the potential difference of the cathode to anode peaks of RGO/S is much higher $(0.497 \mathrm{~V})$ than those of the NOGB/S $(0.309 \mathrm{~V})$ and GB/S $(0.336 \mathrm{~V})$. This indicates the robust electrochemical kinetics for the transformation of $\mathrm{LiS}_{2} / \mathrm{Li}_{2} \mathrm{~S}_{2}$ to $\mathrm{S}_{8}$ in NOGB [44]. Furthermore, the $\mathrm{CV}$ curves of NOGB/S in the following cycles are almost overlapped when compared with GB/S and RGO/S (Fig. S8), indicating the high chemical reversibility.

The galvanostatic charge-discharge curves of NOGB/S at different rates show typical two plateaus between 1.6 and $2.8 \mathrm{~V}$ (Fig. 3b). The unabridged plateaus are still maintained even at a very high rate of $5 \mathrm{C}$, indicating the remarkable electrochemical kinetics. The corresponding rate performance of $\mathrm{NOGB} / \mathrm{S}$ was measured at various rates and then back to $0.1 \mathrm{C}$ (Fig. 3c). Obviously, the NOGB/S exhibits high capacities of $1282,1081,948,858,683,530$, and $433 \mathrm{mAh} \mathrm{g}^{-1}$ at $0.1,0.2,0.5,1,2,5$, and $10 \mathrm{C}$, respectively. (The capacities are calculated as the average values of the five cycles.) When the current density turns back to $0.1 \mathrm{C}$, the capacity of NOGB/S restores to a high value of $965 \mathrm{mAh} \mathrm{g}^{-1}$. The values are much higher than those of $\mathrm{GB} / \mathrm{S}$ and RGO/S, and most of the other composite materials reported in the studies (Fig. 3d) [45-48]. The electrochemical kinetics were further studied by EIS (Fig. 3e). The semicircles in the middle frequency region of the Nyquist plots correspond to the charge transfer process, the tail associated with the semi-infinite Warburg diffusion process of $\mathrm{Li}^{+}$. The EIS fitting results of $R_{\mathrm{S}}$ (bulk resistance), $R_{\mathrm{ct}}$ (charge transfer resistance), and $Z_{\mathrm{W}}$ (semi-infinite Warburg diffusion resistance) [49] are provided in Table S3. As the sulfur confined in the $\mathrm{GB} / \mathrm{S}$ and $\mathrm{NOGB} / \mathrm{S}$ shows a thin layer structure and fully contacts with the conductive graphene frameworks, they show about twenty times lower $R_{\mathrm{ct}}$ values 

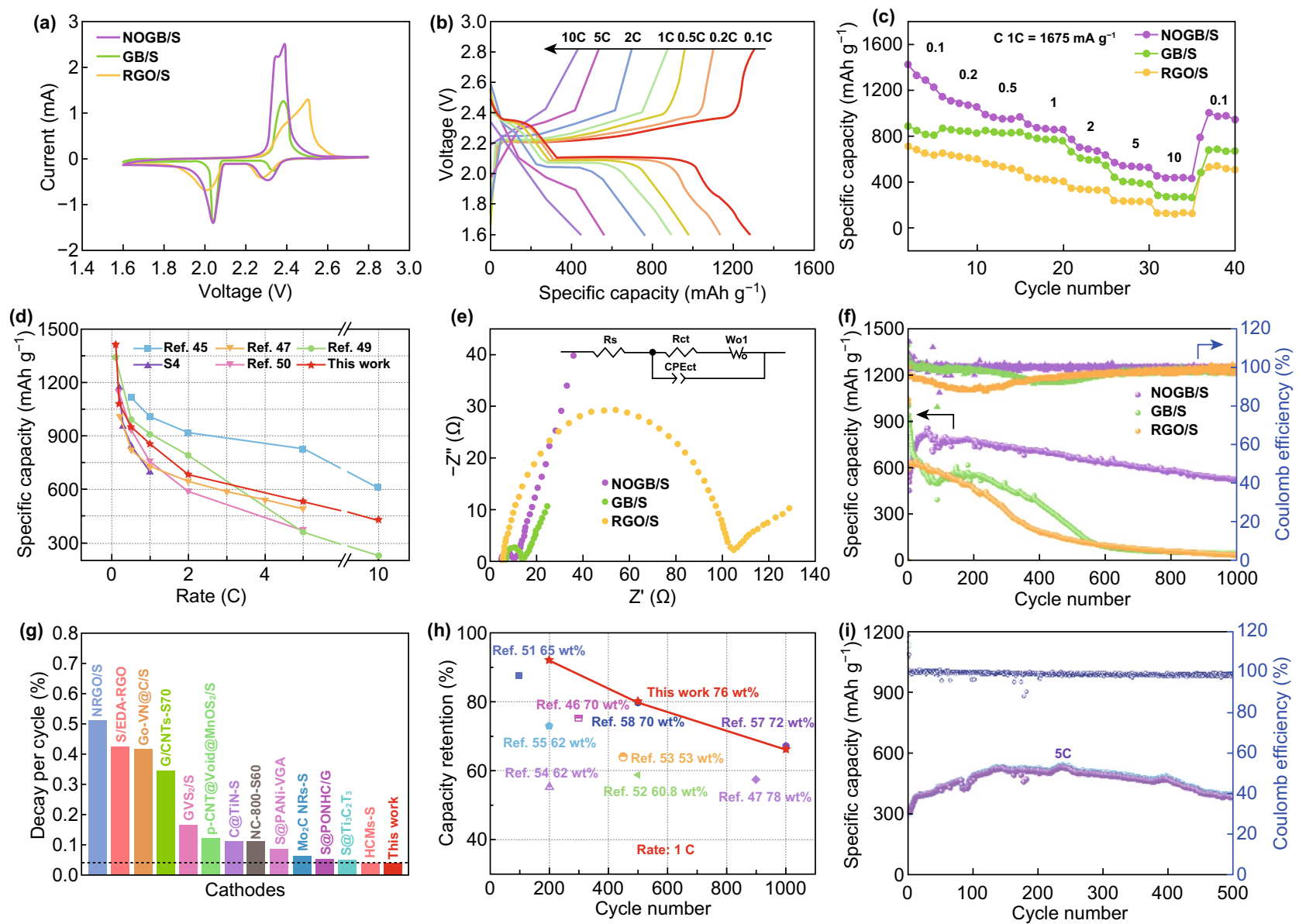

Fig. 3 a CV curves for the first cycle of NOGB/S, GB/S, and RGO/S. b Galvanostatic charge/discharge profiles of the NOGB/S at different rates. c Rate capability of the NOGB/S, GB/S, and RGO/S. d Rate capacity of the NOGB/S compared with other composites reported in the literature. e Nyquist plots of NOGB/S, GB/S, and RGO/S by using fresh cells; the inset is the relevant equivalent circuit model. f Comparison of long-term cyclic properties and $\mathrm{CE}$ at $1 \mathrm{C}$. $\mathrm{g}$ Comparison of the capacity decay rate (per cycle) of the NOGB/S and previously reported materials. (The dashed line corresponds to the decay rate of $0.038 \%$.) h Comparison of capacity retention of the NOGB/S and previously reported electrodes at 1C (with the similar S contents in the composites). The comparison was at the same electrolyte system and similar sulfur loadings. $\mathbf{i}$ Long-term cyclic performance of the NOGB/S at $5 \mathrm{C}$

than the RGO/S with large sulfur particles on the surface. Through N doping, the NOGB/S shows the lowest $R_{\mathrm{ct}}$ and $Z_{\mathrm{w}}$ values, and thus the best electrochemical kinetics among the samples.

The cycle performance of the NOGB/S, GB/S, and $\mathrm{RGO} / \mathrm{S}$ at $1 \mathrm{C}$ was investigated after pre-activation in the first two cycles at $0.05 \mathrm{C}$ (Fig. 3f). Notably, a gradual increase in discharge capacity was observed during the initial first several cycles due to an electrochemical activation process [50], and the NOGB/S reaches its highest capacity of $859 \mathrm{mAh} \mathrm{g}^{-1}$ after activation in the first several cycles. It shows an outstanding cycle stability with a very low capacity fading rate of only $0.038 \%$ per cycle, maintaining a high-capacity retention of $526 \mathrm{mAh} \mathrm{g}^{-1}(61.2 \%)$. By contrast, the retained capacities of GB/S and RGO/S after 1000 cycles are only 54.9 and $39.1 \mathrm{mAh} \mathrm{g}^{-1}$. Moreover, the coulombic efficiency of NOGB/S is $99.8 \%$, also higher than those of GB/S (97.6\%) and RGO/S (94.6\%), indicating the good reversibility of NOGB/S at high sulfur content. The stability of NOGB/S is better than most of the previously reported electrode materials such as HCMs [47], C@TiN [48], Co-VN@C [46], and some metal oxide-based composites (Fig. 3g, h and Table S4) [46, 47, 51-58]. Notably, the comparison was basically made under the same electrolyte system with same content of $\mathrm{LiNO}_{3}$. In addition, when charge-discharge at $5 \mathrm{C}$, the $\mathrm{NOGB} / \mathrm{S}$ also shows a large 
reversible capacity of 477 and $472 \mathrm{mAh} \mathrm{g}^{-1}$ after 100 and 400 cycles, respectively. The capacity remains $379 \mathrm{mAh} \mathrm{g}^{-1}$ after 500 cycles with a high coulombic efficiency about 98.6\% (Fig. 3i). The electrochemical performance of the NOGB hosts prepared at different thermal treatment temperatures was also investigated (Fig. S9). We found that $800{ }^{\circ} \mathrm{C}$ was the optimized temperature due to the balance of electrical conductivity and heteroatom content $[56,59$, 60]. The NOGB/S electrode with a high sulfur loading of $4.4 \mathrm{mg} \mathrm{cm}^{-2}$ was also measured according to the commercialized cathode capacity. An initial discharge capacity of $1373 \mathrm{mAh} \mathrm{g}^{-1}$ is achieved at $0.1 \mathrm{C}$ (Fig. S10), leading to an area capacity of $6.0 \mathrm{mAh} \mathrm{cm}{ }^{-2}$. The capacity is maintained at $3.3 \mathrm{mAh} \mathrm{cm}^{-2}$ after 50 cycles. The good cycle stability clearly demonstrates the advantage of NOGB structure.

To have an insight into the outstanding performance, the discharge curves at different rates of the samples (Fig. 4a-c) were divided into the high-plateau capacity $\left(Q_{\mathrm{H}}\right.$, the adsorption capacity of polysulfide) and low-plateau capacity $\left(Q_{\mathrm{L}}, \mathrm{Li}^{+} / \mathrm{e}^{-}\right.$transport in the electrode), as shown in Fig. $4 \mathrm{~d}$, e. The soluble $\mathrm{Li}_{2} \mathrm{~S}_{x}(4 \leq x \leq 8)$ species are formed when discharging at the high plateau of $2.35 \mathrm{~V}$. The NOGB/S has a high $Q_{\mathrm{H}}$ value, indicating the suppression of the shuttle effect. On the other hand, the insoluble $\mathrm{Li}_{2} \mathrm{~S} / \mathrm{Li}_{2} \mathrm{~S}_{2}$ species are generated at discharge low plateau around $2.1 \mathrm{~V}$. The NOGB/S also has a high $Q_{\mathrm{L}}$ value, indicating the fast conversion ability of soluble polysulfide to insoluble $\mathrm{Li}_{2} \mathrm{~S} / \mathrm{Li}_{2} \mathrm{~S}_{2}$. Moreover, from the UV-Vis absorption spectra, the two obvious peaks around 300 and $370 \mathrm{~nm}$ are attributed to the dissolution of $\mathrm{Li}_{2} \mathrm{~S}_{6} / \mathrm{Li}_{2} \mathrm{~S}_{4}$ and $\mathrm{Li}_{2} \mathrm{~S}_{4}$, respectively (Fig. 4f) [58]. The electrolyte containing NOGB/S electrode presents a weaker absorption intensity, and the solution color is nearly close to clean when comparing to the electrolyte containing $\mathrm{GB} / \mathrm{S}$ or $\mathrm{RGO} / \mathrm{S}$ electrode. We also disassembled the batteries after 50 cycles and found that the separator for NOGB/S electrode shows a clean surface, demonstrating the
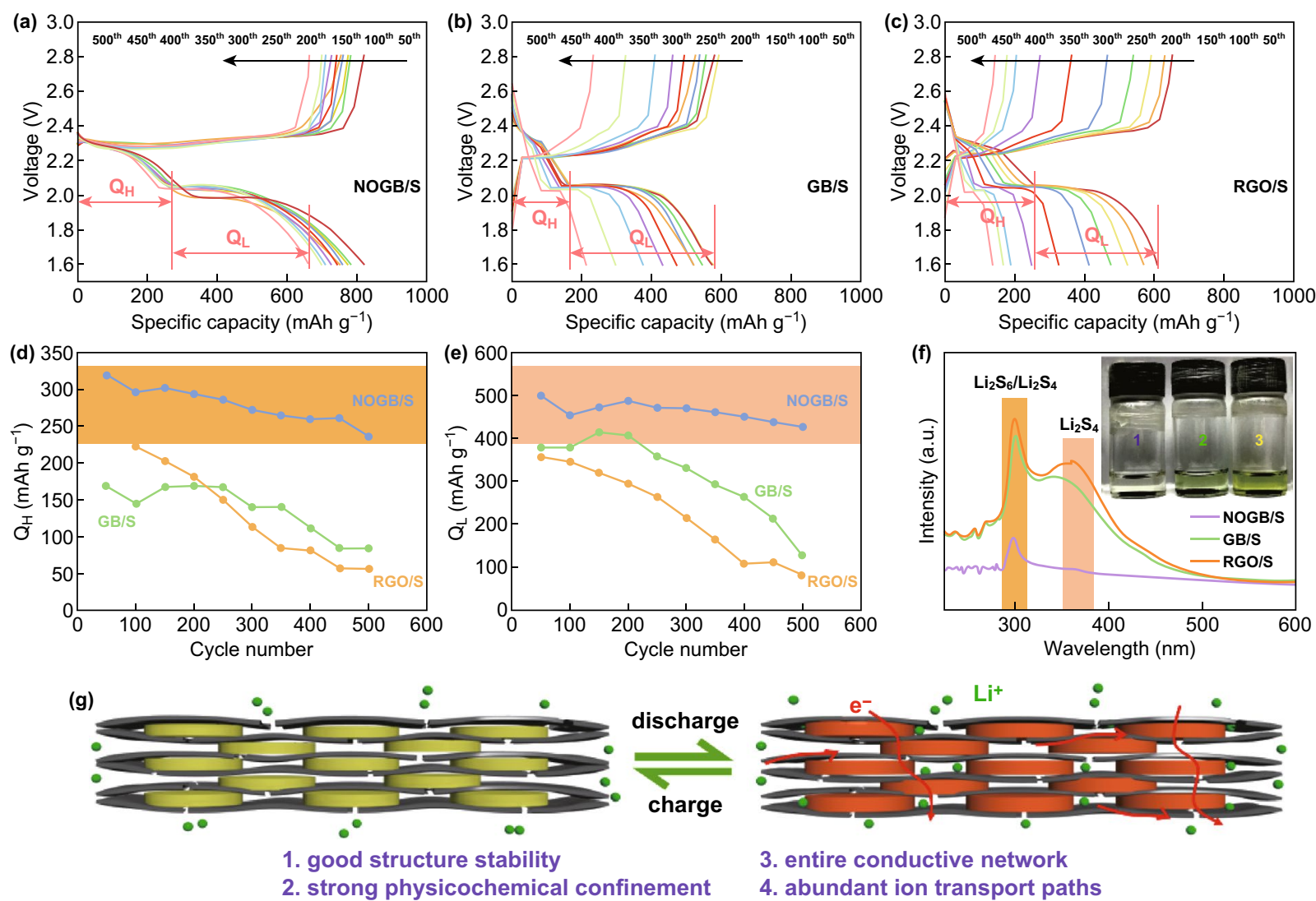

3. entire conductive network

2. strong physicochemical confinement

4. abundant ion transport paths

Fig. 4 Galvanostatic charge-discharge curves at a rate of $1 \mathrm{C}$ for the a NOGB/S, b GB/S, and $\mathbf{c}$ RGO/S. d $\mathrm{Q}_{\mathrm{H}}$ and e $\mathrm{Q}_{\mathrm{L}}$ values through cycling of the three electrodes. f UV-Vis absorption spectra collected from the blank electrolyte solutions soaked with (1) NOGB/S, (2) GB/S, and (3) $\mathrm{RGO} / \mathrm{S}$ electrodes after 50 cycles at $1 \mathrm{C}$, respectively. The inset photograph shows the color comparison of the solutions containing the corresponding electrodes. $\mathrm{g}$ Schematic illustration of the NOGB as advanced sulfur host for LSBs 
strong physicochemical confinement of polysulfides (Fig. S11).

XPS curves of the NOGB/S and GB/S electrodes after discharging to $2.3 \mathrm{~V}$ at $0.1 \mathrm{C}$ (formation the long-chain polysulfides, $\mathrm{Li}_{2} \mathrm{~S}_{x}, 4 \leq x \leq 8$ ) were further used to investigate the role of functional groups on the chemical adsorption of polysulfides. A single symmetric peak in GB/S electrode at $55.7 \mathrm{eV}$ is corresponding to the $\mathrm{Li}-\mathrm{S}$ bond (Fig. S12). The Li $1 \mathrm{~s}$ XPS spectrum of NOGB/S electrode shows an asymmetric peak corresponds to the $\mathrm{Li}-\mathrm{S}(55.6 \mathrm{eV})$ and $\mathrm{Li}-\mathrm{N}$ $(56.3 \mathrm{eV})$ bonds $[47,61]$. The additional peak proves that the nitrogen-bearing functional groups in NOGB have great capability to absorb polysulfides.

The outstanding electrochemical performance of NOGB/S is originated from the unique structure of NOGB host, as illustrated in Fig. 4g. First, the sulfur is sandwiched in the graphene dents and fully attached on the $\mathrm{N}, \mathrm{O}$ co-doped graphene nanosheets. The unique ink-bottle-like mesopores and highly doped heteroatoms lead to the strong physicochemical confinement of polysulfides during cycling. Second, the good contact between the ultrathin sulfur platelets and graphene scaffold ensures good electrical conductivity. And the small micropores on the graphene sheets promote fast $\mathrm{Li}^{+}$transport in the blocks, leading to the robust electrochemical kinetics. Third, the NOGB host can also buffer the large volume change of sulfur during cycling due to good flexibility of the graphene nanosheets.

\section{Conclusion}

In summary, we have prepared $\mathrm{N}, \mathrm{O}$ co-doped graphene layered blocks as sulfur host for LSBs through the modified Hummers' method and subsequent thermal treatment in the $\mathrm{NH}_{3}$ atmosphere. The NOGB shows a layered stacking structure with many dents on the graphene sheets, high $\mathrm{N}$ and $\mathrm{O}$ content, and many micropores. Owing to the unique structure, thin sulfur platelets are strongly confined in the graphene dents, enabling good conductivity, robust electrochemical kinetics, and good structure stability. The NOGB/S shows a high capacity of $1413 \mathrm{mAh} \mathrm{g}^{-1}$ at $0.1 \mathrm{C}$, good rate performance ( $433 \mathrm{mAh} \mathrm{g}^{-1}$ at $10 \mathrm{C}$ ), and remarkable longterm cyclic performance. (Average decay rate is $0.038 \%$ for 1000 cycles at 1 C.) This strategy may open up an effective route for the design of advanced carbon-based sulfur host materials for achieving high-performance LSBs.
Acknowledgements This work was supported by the National Natural Science Foundation of China (Nos. 51672055, 51972342, 51872656, and 51702275), the Taishan Scholar Project of Shandong Province (ts20190922), the Key Basic Research Project of Natural Science Foundation of Shandong Province (ZR2019ZD51), the Xinjiang Tianshan Xuesong Project (2018XS28), the Scientific Research Program of the Higher Education Institution of Xinjiang (XJEDU2017S003), and the Xinjiang Tianchi Doctoral Project.

Open Access This article is licensed under a Creative Commons Attribution 4.0 International License, which permits use, sharing, adaptation, distribution and reproduction in any medium or format, as long as you give appropriate credit to the original author(s) and the source, provide a link to the Creative Commons licence, and indicate if changes were made. The images or other third party material in this article are included in the article's Creative Commons licence, unless indicated otherwise in a credit line to the material. If material is not included in the article's Creative Commons licence and your intended use is not permitted by statutory regulation or exceeds the permitted use, you will need to obtain permission directly from the copyright holder. To view a copy of this licence, visit http://creativecommons.org/licenses/by/4.0/.

Electronic supplementary material The online version of this article (https://doi.org/10.1007/s40820-020-00477-3) contains supplementary material, which is available to authorized users.

\section{References}

1. X. Ji, L.F. Nazar, Advances in Li-S batteries. J. Mater. Chem. 20(44), 9821-9826 (2010). https://doi.org/10.1039/b925751a

2. M. Jana, R. Xu, X.-B. Cheng, J.S. Yeon, J.M. Park, J.-Q. Huang, Q. Zhang, H.S. Park, Rational design of two-dimensional nanomaterials for lithium-sulfur batteries. Energy Environ. Sci. (2019). https://doi.org/10.1039/c9ee02049g

3. G. Li, S. Wang, Y. Zhang, M. Li, Z. Chen, J. Lu, Revisiting the role of polysulfides in lithium-sulfur batteries. Adv. Mater. 30(22), e1705590 (2018). https://doi.org/10.1002/adma.20170 5590

4. Z. Chen, J. Chen, F. Bu, P.O. Agboola, I. Shakir, Y. Xu, Double-holey-heterostructure frameworks enable fast, stable and simultaneous ultrahigh gravimetric, areal, and volumetric lithium storage. ACS Nano 12, 12879-12887 (2018). https:// doi.org/10.1021/acsnano.8b08071

5. F. Liu, Q. Xiao, H.B. Wu, F. Sun, X. Liu et al., Regenerative polysulfide-scavenging layers enabling lithium-sulfur batteries with high energy density and prolonged cycling life. ACS Nano 11(3), 2697-2705 (2017). https://doi.org/10.1021/acsna no.6b07603

6. Q. Li, Y. Song, R. Xu, L. Zhang, J. Gao et al., Biotemplating growth of nepenthes-like $\mathrm{N}$-doped graphene as a bifunctional polysulfide scavenger for $\mathrm{Li}-\mathrm{S}$ batteries. ACS Nano 12(10), 10240-10250 (2018). https://doi.org/10.1021/acsna no. 8 b05246 
7. Y. Pang, J.S. Wei, Y.G. Wang, Y.Y. Xia, Synergetic protective effect of the ultralight MWCNTs/NCQDs modified separator for highly stable lithium-sulfur batteries. Adv. Energy Mater. 8(10), 1702288 (2018). https://doi.org/10.1002/aenm.20170 2288

8. Y.F. Yang, J.P. Zhang, Highly stable lithium-sulfur batteries based on laponite nanosheet-coated celgard separators. Adv. Energy Mater. 8(25), 1801778 (2018). https://doi.org/10.1002/ aenm.201801778

9. M. Liu, Q. Li, X. Qin, G. Liang, W. Han et al., Suppressing self-discharge and shuttle effect of lithium-sulfur batteries with $\mathrm{V}_{2} \mathrm{O}_{5}$-decorated carbon nanofiber interlayer. Small 13(12), 1602539 (2017). https://doi.org/10.1002/smll.20160 2539

10. H. Pan, K.S. Han, M.H. Engelhard, R. Cao, J. Chen et al., Lean electrolyte batteries: addressing passivation in lithium-sulfur battery under lean electrolyte condition. Adv. Funct. Mater. 28(38), 1870275 (2018). https://doi.org/10.1002/adfm.20187 0275

11. H. Xu, S. Wang, A. Manthiram, Hybrid lithium-sulfur batteries with an advanced gel cathode and stabilized lithium-metal anode. Adv. Energy Mater. (2018). https://doi.org/10.1002/ aenm.201800813

12. S.S. Zhang, Role of $\mathrm{LiNO}_{3}$ in rechargeable lithium/sulfur battery. Electrochim. Acta 70, 344-348 (2012). https://doi. org/10.1016/j.electacta.2012.03.081

13. M. Agostini, D.H. Lim, M. Sadd, J.Y. Hwang, S. Brutti et al., Rational design of low cost and high energy lithium batteries through tailored fluorine-free electrolyte and nanostructured S/C composite. Chemsuschem 11(17), 2981-2986 (2018). https://doi.org/10.1002/cssc.201801017

14. H. Shi, W. Lv, C. Zhang, D.-W. Wang, G. Ling, Y. He, F. Kang, Q.-H. Yang, Functional carbons remedy the shuttling of polysulfides in lithium-sulfur batteries: confining, trapping, blocking, and breaking up. Adv. Funct. Mater. (2018). https:// doi.org/10.1002/adfm.201800508

15. Z. Zeng, X. Liu, Sulfur immobilization by "chemical anchor" to suppress the diffusion of polysulfides in lithium-sulfur batteries. Adv. Mater. Interfaces 5(4), 1701274 (2018). https:// doi.org/10.1002/admi.201701274

16. J. Lee, J. Oh, Y. Jeon, Y. Piao, Multi-heteroatom-doped hollow carbon attached on graphene using $\mathrm{LiFePO}_{4}$ nanoparticles as hard templates for high-performance lithium-sulfur batteries. ACS Appl. Mater. Interfaces. 10(31), 26485-26493 (2018). https://doi.org/10.1021/acsami.8b00925

17. X. Ma, G. Ning, Y. Wang, X. Song, Z. Xiao, L. Hou, W. Yang, J. Gao, Y. Li, S-doped mesoporous graphene microspheres: a high performance reservoir material for Li-S batteries. Electrochim. Acta 269, 83-92 (2018). https://doi.org/10.1016/j. electacta.2018.02.163

18. H. Tang, J. Yang, G. Zhang, C. Liu, H. Wang, Q. Zhao, J. $\mathrm{Hu}$, Y. Duan, F. Pan, Self-assembled N-graphene nanohollows enabling ultrahigh energy density cathode for $\mathrm{Li}-\mathrm{S}$ batteries. Nanoscale 10(1), 386-395 (2017). https://doi.org/10.1039/ c7nr06731c
19. P. Wu, L.H. Chen, S.S. Xiao, S. Yu, Z. Wang, Y. Li, B.L. $\mathrm{Su}$, Insight into the positive effect of porous hierarchy in S/C cathodes on the electrochemical performance of $\mathrm{Li}-\mathrm{S}$ batteries. Nanoscale 10(25), 11861-11868 (2018). https://doi. org/10.1039/c8nr03290d

20. H. Wu, L. Xia, J. Ren, Q. Zheng, C. Xu, D. Lin, A high-efficiency N/P co-doped graphene/CNT@porous carbon hybrid matrix as a cathode host for high performance lithium-sulfur batteries. J. Mater. Chem. A 5(38), 20458-20472 (2017). https ://doi.org/10.1039/c7ta06504c

21. X.-Q. Zhang, B. He, W.-C. Li, A.-H. Lu, Hollow carbon nanofibers with dynamic adjustable pore sizes and closed ends as hosts for high-rate lithium-sulfur battery cathodes. Nano Res. 11(3), 1238-1246 (2018). https://doi.org/10.1007/s 1227 4-017-1737-6

22. G. Li, W. Lei, D. Luo, Y. Deng, Z. Deng, D. Wang, A. Yu, Z. Chen, Stringed "tube on cube" nanohybrids as compact cathode matrix for high-loading and lean-electrolyte lithiumsulfur batteries. Energy Environ. Sci. 11, 2372-2381 (2018). https://doi.org/10.1039/c8ee01377b

23. H. Zhang, Q. Gao, W. Qian, H. Xiao, Z. Li, L. Ma, X. Tian, Binary hierarchical porous graphene/pyrolytic carbon nanocomposite matrix loaded with sulfur as a high-performance Li-S battery cathode. ACS Appl. Mater. Interfaces. 10(22), 18726-18733 (2018). https://doi.org/10.1021/acsami.8b03806

24. P. Shi, Y. Wang, X. Liang, Y. Sun, S. Cheng, C. Chen, H. Xiang, Simultaneously exfoliated boron-doped graphene sheets to encapsulate sulfur for applications in lithium-sulfur batteries. ACS Sustain. Chem. Eng. 6(8), 9661-9670 (2018). https://doi.org/10.1021/acssuschemeng.8b00378

25. S. Liu, J. Li, X. Yan, Q. Su, Y. Lu et al., Superhierarchical cobalt-embedded nitrogen-doped porous carbon nanosheets as two-in-one hosts for high-performance lithium-sulfur batteries. Adv. Mater. 30(12), e1706895 (2018). https://doi. org/10.1002/adma.201706895

26. H.-E. Wang, X. Li, N. Qin, X. Zhao, H. Cheng, G. Cao, W. Zhang, Sulfur-deficient $\mathrm{MoS}_{2}$ grown inside hollow mesoporous carbon as a functional polysulfide mediator. J. Mater. Chem. A 7(19), 12068-12074 (2019). https://doi. org/10.1039/c9ta01722d

27. J. He, G. Hartmann, M. Lee, G.S. Hwang, Y. Chen, A. Manthiram, Freestanding $1 \mathrm{~T} \mathrm{MoS}_{2}$ /graphene heterostructures as a highly efficient electrocatalyst for lithium polysulfides in $\mathrm{Li}-\mathrm{S}$ batteries. Energy Environ. Sci. 12(1), 344-350 (2019). https:// doi.org/10.1039/c8ee03252a

28. L. Meng, Y. Yao, J. Liu, Z. Wang, D. Qian, L. Zheng, B.-L. $\mathrm{Su}, \mathrm{H}$.-E. Wang, $\mathrm{MoSe}_{2}$ nanosheets as a functional host for lithium-sulfur batteries. J. Energy Chem. 47, 241-247 (2020). https://doi.org/10.1016/j.jechem.2020.02.003

29. W. Dong, D. Wang, X. Li, Y. Yao, X. Zhao et al., Bronze $\mathrm{TiO}_{2}$ as a cathode host for lithium-sulfur batteries. J. Energy Chem. 48, 259-266 (2020). https://doi.org/10.1016/j.jeche m.2020.01.022

30. H.-E. Wang, K. Yin, N. Qin, X. Zhao, F.-J. Xia et al., Oxygen-deficient titanium dioxide as a functional host for 
lithium-sulfur batteries. J. Mater. Chem. A 7(17), 1034610353 (2019). https://doi.org/10.1039/c9ta01598a

31. Y. Wang, R. Zhang, J. Chen, H. Wu, S. Lu et al., Enhancing catalytic activity of titanium oxide in lithium-sulfur batteries by band engineering. Adv. Energy Mater. 9(24), 1900953 (2019). https://doi.org/10.1002/aenm.201900953

32. G. Yuan, H. Jin, Y. Jin, L. Wu, Hybrids of $\mathrm{MnO}_{2}$ nanoparticles anchored on graphene sheets as efficient sulfur hosts for high-performance lithium sulfur batteries. J. Solid State Electrochem. 22(3), 693-703 (2017). https://doi.org/10.1007/ s10008-017-3799-5

33. Y. Zhang, X. Liu, L. Wu, W. Dong, F. Xia et al., A flexible, hierarchically porous $\mathrm{PANI} / \mathrm{MnO}_{2}$ network with fast channels and an extraordinary chemical process for stable fast-charging lithium-sulfur batteries. J. Mater. Chem. A 8(5), 2741-2751 (2020). https://doi.org/10.1039/c9ta12135h

34. T.Z. Hou, X. Chen, H.J. Peng, J.Q. Huang, B.Q. Li, Q. Zhang, B. Li, Design principles for heteroatom-doped nanocarbon to achieve strong anchoring of polysulfides for lithium-sulfur batteries. Small 12(24), 3283-3291 (2016). https://doi. org/10.1002/smll.201600809

35. H. Yang, X. Zhang, W. Zhu, F. Wang, Y. Li, Q. Fan, H. Xiao, F. Zhang, Graphene oxide induced growth of nitrogen-doped carbon nanotubes as a 1D/2D composite for high-performance lithium-sulfur batteries. ChemElectroChem 6(4), 1115-1121 (2019). https://doi.org/10.1002/celc.201801445

36. M. Zhang, C. Yu, J. Yang, C. Zhao, Z. Ling, J. Qiu, Nitrogen-doped tubular/porous carbon channels implanted on graphene frameworks for multiple confinement of sulfur and polysulfides. J. Mater. Chem. A 5(21), 10380-10386 (2017). https://doi.org/10.1039/c7ta01512g

37. F. Pei, T. An, J. Zang, X. Zhao, X. Fang, M. Zheng, Q. Dong, N. Zheng, From hollow carbon spheres to N-doped hollow porous carbon bowls: rational design of hollow carbon host for Li-S batteries. Adv. Energy Mater. 6(8), 1502539 (2016). https://doi.org/10.1002/aenm.201502539

38. L. Sheng, L. Jiang, T. Wei, Z. Fan, High volumetric energy density asymmetric supercapacitors based on well-balanced graphene and graphene- $\mathrm{MnO}_{2}$ electrodes with densely stacked architectures. Small 12(37), 5217-5227 (2016). https://doi.org/10.1002/smll.201601722

39. Q.H. Zhou, J. Chang, Y.T. Jiang, T. Wei, L.Z. Sheng, Z.J. Fan, Fast charge rate supercapacitors based on nitrogendoped aligned carbon nanosheet networks. Electrochim. Acta 251, 91-98 (2017). https://doi.org/10.1016/j.elect acta.2017.08.106

40. L.H. Zhang, J.M. Yue, T. Wei, Z. Liu, J.L. Zhou et al., Densely pillared holey-graphene block with high-level nitrogen doping enabling ultra-high volumetric capacity for lithium ion storage. Carbon 142, 327-336 (2019). https:// doi.org/10.1016/j.carbon.2018.10.070

41. J. Wang, X. Yan, Z. Zhang, H. Ying, R. Guo, W. Yang, W.Q. Han, Facile preparation of high-content N-doped CNT microspheres for high-performance lithium storage. Adv. Funct. Mater. 29(39), 1904819 (2019). https://doi. org/10.1002/adfm.201904819
42. N. Wang, Z. Xu, X. Xu, T. Liao, B. Tang, Z. Bai, S. Dou, Synergistically enhanced interfacial interaction to polysulfide via $\mathrm{N}$, O dual-doped highly porous carbon microrods for advanced lithium-sulfur batteries. ACS Appl. Mater. Interfaces. 10(16), 13573-13580 (2018). https://doi.org/10.1021/acsami.8b02084

43. S.-K. Park, J.-K. Lee, Y.C. Kang, Yolk-shell structured assembly of bamboo-like nitrogen-doped carbon nanotubes embedded with Co nanocrystals and their application as cathode material for Li-S batteries. Adv. Funct. Mater. 28(18), 1705264 (2018). https://doi.org/10.1002/adfm.201705264

44. X. Zhu, W. Zhao, Y. Song, Q. Li, F. Ding, J. Sun, L. Zhang, Z. Liu, In situ assembly of 2D conductive vanadium disulfide with graphene as a high-sulfur-loading host for lithium-sulfur batteries. Adv. Energy Mater. (2018). https ://doi.org/10.1002/aenm.201800201

45. J. Zhang, J.-Y. Li, W.-P. Wang, X.-H. Zhang, X.-H. Tan, W.-G. Chu, Y.-G. Guo, Microemulsion assisted assembly of $3 \mathrm{D}$ porous $\mathrm{S} / \mathrm{graphene} @ \mathrm{~g}-\mathrm{C}_{3} \mathrm{~N}_{4}$ hybrid sponge as freestanding cathodes for high energy density Li-S batteries. Adv. Energy Mater. 8(14), 1702839 (2018). https://doi. org/10.1002/aenm.201702839

46. W. Ren, L. Xu, L. Zhu, X. Wang, X. Ma, D. Wang, Cobaltdoped vanadium nitride yolk-shell nanospheres @ carbon with physical and chemical synergistic effect for advanced Li-S batteries. ACS Appl. Mater. Interfaces. 10(14), 11642-11651 (2018). https://doi.org/10.1021/acsami.7b18955

47. X. Zhou, J. Tian, Q. Wu, J. Hu, C. Li, N/O dual-doped hollow carbon microspheres constructed by holey nanosheet shells as large-grain cathode host for high loading $\mathrm{Li}-\mathrm{S}$ batteries. Energy Storage Mater. 24, 644-654 (2020). https://doi. org/10.1016/j.ensm.2019.06.009

48. Y. Wang, R. Zhang, Y.-C. Pang, X. Chen, J. Lang et al., Carbon@titanium nitride dual shell nanospheres as multifunctional hosts for lithium sulfur batteries. Energy Storage Mater. 16, 228-235 (2019). https://doi.org/10.1016/j. ensm.2018.05.019

49. Z.X. Cao, R.R. Zhang, M.J. Shi, G.S. Zhu, M.G. Yang, H.S. Zhang, Y. Qiao, S.T. Yang, Rational design oxygen and sulfur dual-doped 3D hierarchical porous carbons for high-performance lithium-sulfur batteries. J. Electrochem. Soc. 165(2), A31-A39 (2018). https://doi.org/10.1149/2.0041802jes

50. J.-Q. Huang, W.G. Chong, Q. Zheng, Z.-L. Xu, J. Cui, S. Yao, C. Wang, J.-K. Kim, Understanding the roles of activated porous carbon nanotubes as sulfur support and separator coating for lithium-sulfur batteries. Electrochim. Acta 268, 1-9 (2018). https://doi.org/10.1016/j.electacta.2018.02.096

51. Q. Liu, J. Zhang, S.A. He, R. Zou, C. Xu et al., Stabilizing lithium-sulfur batteries through control of sulfur aggregation and polysulfide dissolution. Small (2018). https://doi.org/10.1002/ smll.201703816

52. H. Wu, L. Xia, J. Ren, Q. Zheng, F. Xie, W. Jie, C. Xu, D. Lin, A multidimensional and nitrogen-doped graphene/hierarchical porous carbon as a sulfur scaffold for high performance lithium sulfur batteries. Electrochim. Acta 278, 83-92 (2018). https://doi.org/10.1016/j.electacta.2018.05.032 
53. H. Xu, A. Manthiram, Hollow cobalt sulfide polyhedra-enabled long-life, high areal-capacity lithium-sulfur batteries. Nano Energy 33, 124-129 (2017). https://doi.org/10.1016/j. nanoen.2017.01.007

54. F. Sun, H. Tang, B. Zhang, X. Li, C. Yin et al., PEO-linked $\mathrm{MoS}_{2}$-graphene nanocomposites with 2D polar-nonpolar amphoteric surfaces as sulfur hosts for high-performance Li-S batteries. ACS Sustainable Chem. Eng. 6(1), 974-982 (2017). https://doi.org/10.1021/acssuschemeng.7b03306

55. Y. Zhang, J. Ren, Y. Zhao, T. Tan, F. Yin, Y. Wang, A porous 3D-rGO@MWCNT hybrid material as Li-S battery cathode. Beilstein J Nanotechnol. 10, 514-521 (2019). https://doi. org/10.3762/bjnano.10.52

56. J. Li, C. Xue, B. Xi, H. Mao, Y. Qian, S. Xiong, Heteroatom dopings and hierarchical pores of graphene for synergistic improvement of lithium-sulfur battery performance. Inorg. Chem. Front. 5(5), 1053-1061 (2018). https://doi.org/10.1039/ c8qi00160j

57. F. Li, G. Hu, S. Li, C. Hou, J. Gao, Dual-confined sulfur cathodes based on $\mathrm{SnO}_{2}$-decorated $\mathrm{MoS}_{2}$ microboxes for longlife lithium-sulfur batteries. Electrochim. Acta 340, 135991 (2020). https://doi.org/10.1016/j.electacta.2020.135991
58. T. Chen, Z. Zhang, B. Cheng, R. Chen, Y. Hu, L. Ma, G. Zhu, J. Liu, Z. Jin, Self-templated formation of interlaced carbon nanotubes threaded hollow $\mathrm{Co}_{3} \mathrm{~S}_{4}$ nanoboxes for highrate and heat-resistant lithium-sulfur batteries. J. Am. Chem. Soc. 139(36), 12710-12715 (2017). https://doi.org/10.1021/ jacs.7b06973

59. L. Lai, J.R. Potts, D. Zhan, L. Wang, C.K. Poh et al., Exploration of the active center structure of nitrogen-doped graphenebased catalysts for oxygen reduction reaction. Energy Environ. Sci. 5(7), 7936 (2012). https://doi.org/10.1039/c2ee21802j

60. J. Zhang, M. Huang, B. Xi, K. Mi, A. Yuan, S. Xiong, Systematic study of effect on enhancing specific capacity and electrochemical behaviors of lithium-sulfur batteries. Adv. Energy Mater. 8(2), 1701330 (2018). https://doi.org/10.1002/ aenm.201701330

61. D. Cheng, Y. Zhao, X. Tang, T. An, X. Wang, H. Zhou, D. Zhang, T. Fan, Densely integrated Co, N-codoped graphene @ carbon nanotube porous hybrids for high-performance lithium-sulfur batteries. Carbon 149, 750-759 (2019). https ://doi.org/10.1016/j.carbon.2019.04.108 